\title{
Hydrological Studies for the Assessment of Run-of-River Hydropower Potential and Generation over the Wouri-Nkam River using GIS and Remote Sensing Techniques
}

\author{
Gah-Muti Salvanus Yevalla 1, 2*, Dadjeu Nguemeu Seidou 2, 3, Bang Vu Ngoc ${ }^{3}$, Tran Van Hoi 3 , \\ Tabod Charles Tabod ${ }^{1}$ \\ 1 University of Yaoundé 1, Faculty of Science, Department of Physics, CAMEROON \\ 2 University of Douala, Institute of Fisheries and Aquatic Sciences at Yabassi, Department of Oceanography, \\ CAMEROON \\ ${ }^{3}$ Xuan Thien Africa Investments S.A., VIETNAM
}

*Corresponding Author: gasmsy@gmail.com

Citation: Yevalla, G.-M. S., Seidou, D. N., Ngoc, B. V., Hoi, T. V. and Tabod, T. C. (2018). Hydrological Studies for the Assessment of Run-of-River Hydropower Potential and Generation over the Wouri-Nkam River using GIS and Remote Sensing Techniques. Aquademia: Water, Environment and Technology, 2(1), 02. https://doi.org/10.20897/awet/86712

Published: April 10, 2018

\begin{abstract}
Cameroon has several renewable energy sources, including solar, wind, and hydropower. With the liberalisation of the hydroelectric energy sector in Cameroon, rural communities are yet to feel the impact. Small Hydropower projects should have been developed to curb the acute shortage of electricity within these localities and beyond. This is not the case yet. It is in this respect that this study is carried out: to assess the hydropower potential of the Nkam Division and environs and propose sites for the development of hydroelectricity. Geographical Information System, Remote Sensing techniques, and hydrological models (HEC-HMS) were used. Grid analyses were carried out on the Digital Elevation Models (DEMs) using the Watershed Modelling System software to delineate the catchment basin with the sub-basins. Digital Soil and Land use data were obtained from the Harmonised World Soil Data and World Land use Data respectively, which together were used to calculate the Composite Curve Number in QGIS for the various sub-basins. The curve numbers together with other hydrological parameters were used to develop a HEC-HMS deterministic hydrologic model for the catchment basin. The resulting model was calibrated and validated in HEC-HMS, using precipitation data obtained from the localised Yabassi weather station and discharge values from a gauging station at Yabassi. The calibrated peak discharge produced an absolute error of $3.4 \%$ and a Nash-Sutcliffe value of 0.301 . The hypsometric curve presents a hilly landscape, with $40 \%$ of the surface area having elevations of between 10 to $30 \mathrm{~m}$, favouring the development of small scale hydro systems. The RETScreen software was used for the hydro-energy analyses and the estimated potential power, for a hydraulic head of $20 \mathrm{~m}$, stood at 13,813 kW. The values of the Benefit-Cost Ratio value of 1.3 and the Net Present Value greater than zero show that the project is very practical and profitable. It follows that Small and Medium Run-of-River Hydropower Plants can be developed from the Wouri-Nkam Reach, the significant reach in the river network of the Catchment Basin, with an estimated compensation flow of $133.17 \mathrm{~m}^{3} / \mathrm{s}$ for ecological continuity. The project will reduce about 27,064.8 tons of $\mathrm{CO}_{2}$ from the atmosphere.
\end{abstract}

Keywords: catchment assessment, curve number, hydropower generation, rainfall-runoff models, HECHMS, water management 


\section{INTRODUCTION}

Sustainable industrialization rests on the availability of energy (Dudhani et al., 2006; Fan et al., 2013; Khan and Zaidi, 2015). This energy could be obtained from fossil fuels (with concerns over environmental degradation), large hydropower projects (with concerns of displacement of land and population), and nuclear fuel (with environmental problems). The ever-growing need for power warrants us to explore alternative energy sources. Amongst these alternative sources, stands hydropower on a smaller scale (small, mini, and micro hydropower), given in Table 1, which sustains growth in the power sector. The small hydropower projects need low initial investments, smaller area, shorter planning and construction time, locally trained manpower, indigenous material, and lower power generation cost as compared to larger power projects (Dudhani, et al., 2006). Hydropower in general is an environmentally clean and renewable energy source, contributing by negligible amounts to Green House Gas emissions and other atmospheric pollutions (Dudhani et al., 2006). About 20\% of the electricity of the world is hydropower (Raghu, 2015). The hydropower potential of Cameroon is estimated at $35 \mathrm{GW}$, of which only $2 \%$ had been developed. It is worth noting that $67 \%$ of all electricity generated in the country in 2007 was hydroelectric power (Nations et al., 2009). It is estimated that more than half of the population of Cameroon does not have access to electricity. Extremely, $80 \%$ of the rural areas do not have electricity. This problem is further compounded by the fact that there are no national grids, so $20 \%$ of the generated power is lost during transmission and distribution (Nations et al., 2009). Thus, the development of Small Hydro Systems in Cameroon will be a welcome relief for these rural areas, given that hilly areas with rainy climatic properties have enormous hydropower potential (Coskun et al., 2010).

Table 1. Classification of Hydropower According to Generating Capacity (Tarife et al., 2017).

\begin{tabular}{ll}
\hline Hydropower Class & Generating Capacity \\
\hline Large & $>100 \mathrm{MW}$ \\
\hline Medium & $25-100 \mathrm{MW}$ \\
\hline Small & $1-25 \mathrm{MW}$ \\
\hline Mini & $100 \mathrm{~kW}-1 \mathrm{MW}$ \\
\hline Micro & $5-100 \mathrm{~kW}$ \\
\hline Pico & $<5 \mathrm{~kW}$ \\
\hline
\end{tabular}

The main motivation for this study is the desire to see an improvement in the lives of the people living within this area. Power cuts in Yabassi are very rampant and most of the time, they last for more than two months. The inhabitants resort to burning firewood for domestic activities (harming the environment), solar lamps, and kerosene lamps, as well as generators. Because access to Yabassi is difficult, goods like petrol, kerosene are very expensive. It is also the wish of many that the area should re-experience development, and only the continuous availability of electricity can guarantee it.

Advances in computer technology, with the appearance of Geographic Information System (GIS), in conjunction with rainfall-runoff hydrologic model, usher a variety of hydrological applications, including but not being limited to the drainage pattern delineation in a catchment (Coskun et al., 2010; Dudhani et al., 2006; Kulkarni and Banerjee, 2011; Mirchi et al., 2010; Raghu, 2015). Remotely sensed maps, specifically Digital Elevation Models (DEMs), are analysed to obtain most of the hydrological parameters. The hydrologic model was developed to get the estimated runoff depth and corresponding hydrograph around the gauging station. The design discharge was also estimated for the watershed within the reach of interest, from where the dam is to be constructed. The hydropower capacity for the particular reach is calculated and the design is performed, including a proposed site for construction.

The Catchment Basin of interest drains a very large area, which cuts across four Administrative Regions of Cameroon, which are the Littoral Region, the Centre Region, the South West Region, and the West Region. It is located within 4.35 - 5.81 degrees North latitude and 9.59-11.96 degrees East longitude and covers a surface area of $8,192 \mathrm{~km}^{2}$. The predominant river is the Nkam River, which becomes the Wouri River in the downstream of the catchment. The catchment basin is shown in Figure 1. The climatic condition is of equatorial type, with monthly average temperatures between $22.64{ }^{\circ} \mathrm{C}$ and $28.04{ }^{\circ} \mathrm{C}$, and monthly average precipitation depths between 1 and $92 \mathrm{~mm}$.

\section{DATA AND METHODOLOGY}

The methodology generally consists in obtaining elevation and meteorological data and analysing; developing and calibrating/validating the model with discharge data at a gauging station; calculating a theoretical value for the 


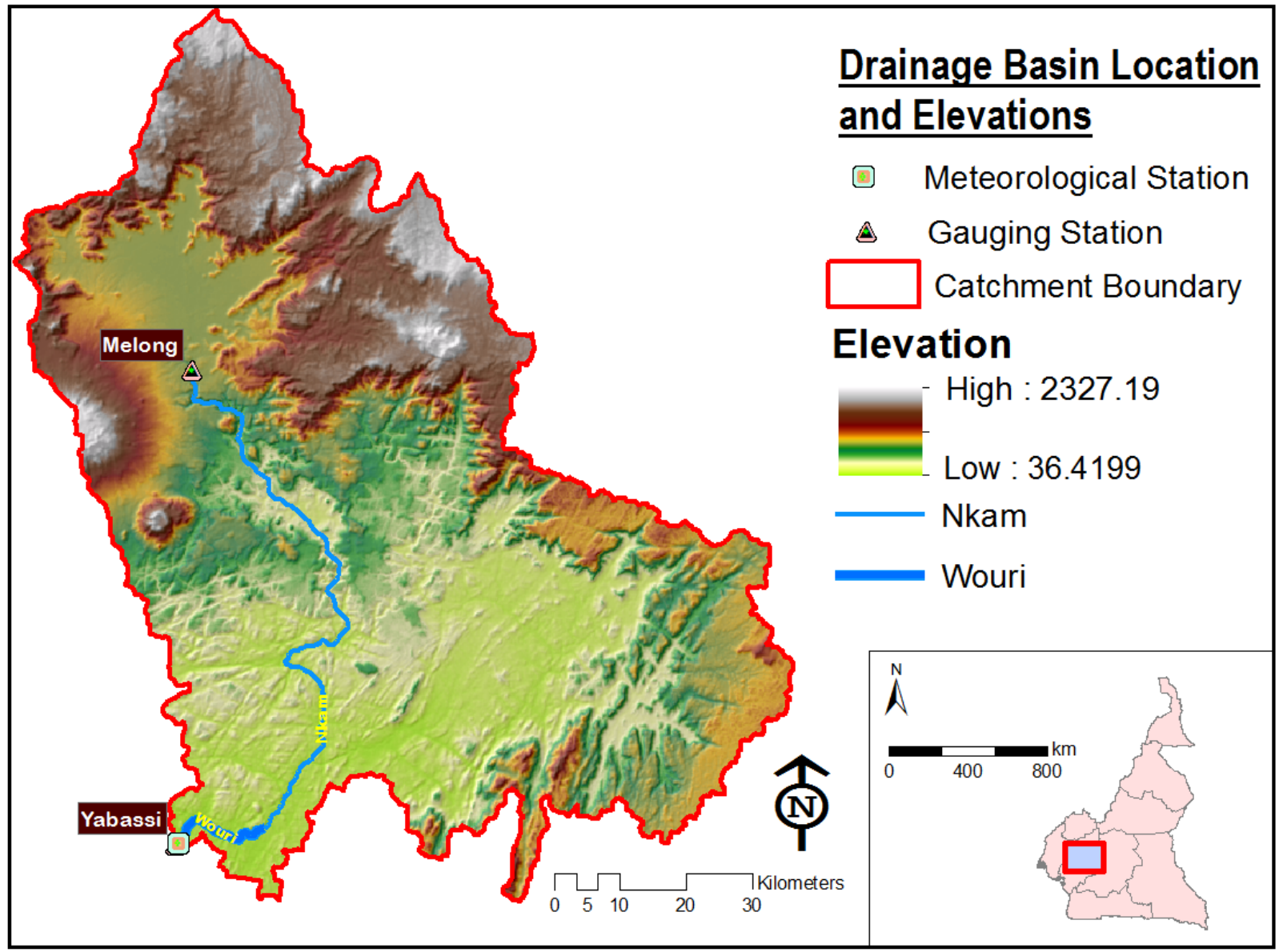

Figure 1. The watershed of interest

potential hydropower of the envisaged area and using multi-criteria analysis for the selection of the hydropower plant site, and calculating the value of the hydropower potential to export to the central grid.

\section{Delineate and Calculate Catchment Parameters}

This first phase of the project makes use of the Watershed Modelling System (WMS) software to obtain hydrological and geometrical parameters of the drainage basin. WMS has web-based data acquisition tools that give access to some of the data required to set and run a hydrologic model as well as a hydraulic model. Using the step-by-step hydrologic modelling wizard of the software, web-service data were downloaded, including Shuttle Radar Topographic Mission (SRTM) - 3-arc-second resolution elevation map, topographic map, as well as soil data and land cover data. Flow directions and flow accumulations were computed by the software, and outflow points chosen. The catchment basin, which is the upslope area that drains to the outlet, is automatically delineated in WMS. A desired modelling approach is selected to simulate processes within the delineated drainage basin.

The HEC-HMS approach, which focuses on runoff, channel routing, and water control structures, is chosen and a (numerical) model is built from the hydrologic and geometric parameters of the catchment basin. This approach is suitable for events and not for long simulations. The resulting model is simulated in the HEC-HMS software, for known hyetographs, using the National Resource Conservation Service - Curve Number (NRCS$\mathrm{CN}$ ) method. Conceptually speaking, the NRCS (formerly, the SCS) method converts a hyetograph into a hydrograph, influenced by soil properties, land cover, abstractions, ground slope, and other factors within the catchment area. It is one of the enduring methods for estimating direct runoff volumes in poorly gauged or ungauged catchments (Fan et al., 2013). Precipitation depths are obtained from the localized weather station at Yabassi. The catchment basin is poorly gauged with just one rainfall data centre, covering the whole of the watershed. If other nearby meteorological stations were available, then the average basin rainfall would have been calculated by constructing Voronoi polygons (Raghu, 2015). The precipitation data are used to calibrate the model with the discharge data from Yabassi. The hydrologic model is validated by simulating reach discharge from the rainfall data. This discharge simulation is necessary to give an idea about the flow that the hydraulic structure will have to contend with. The NRCS method uses a unit hydrograph. It translates excess rainfall depth into a runoff flow. The required parameters to be calculated prior to running the hydrological model include but are not limited 
to the basin lag time $\left(t_{L}\right)$ and the time of concentration $\left(t_{c}\right)$. The formulas for these are given in equations (1) and (2) below:

$$
t_{L}=\frac{(30.48 * L)^{0.8}(S+1)^{0.7}}{1900 Y^{0.5}}
$$

and

$$
t_{c}=\frac{5}{3} t_{L}
$$

where $Y$ is the slope of the catchment basin (\%) and $L$ is the flow length (the longest path along which water flows from the watershed divide to the outlet) $(\mathrm{cm})$.

The NRCS-CN method depends on the value of Curve Number $(\mathrm{CN})$. The general runoff volume from this method is given by equation (3);

$$
Q= \begin{cases}0 & , \quad P \leq 0.2 S \\ \frac{(P-0.2 S)^{2}}{P+0.8 S}, & P>0.2 S\end{cases}
$$

where $P$ is precipitation ( $\mathrm{mm}$ ) and $S$ is potential maximum retention (cm). $S$ is defined in equation (4) as:

$$
S=2.54\left(\frac{1000}{C N}-10\right)
$$

In this study, the value of $C N$ for the catchment (and sub basins) was calculated using an approach similar to that presented by Fan et al.,(2013). Though less sophisticated, it used the soil and land use data together with the TR-55 look-up tables on curve numbers produced by the Department of Agriculture's NRCS of the United States of America. The method consisted in classifying the land use and soil type in terms of categories. Each combination of a land use category and a soil type category was attributed a value for an initial curve number from the TR-55 look-up table. The resulting composite curve number was calculated using the formula in equation (5):

$$
C N_{\text {composite }}=\frac{\sum_{i} C N_{i} * A_{i}}{\sum_{i} A_{i}}
$$

where $A_{i}$ is the area of certain combination of a category of land use and a category of soil type and $C N_{i}$ is the correspondingly associated curve number.

\section{Hydropower Theoretical Capacities and Plant Sites}

The choice for selecting construction sites for hydropower plants depends on the elevation difference and the discharge. These discharge and head values are evaluated using the method presented by Khan and Zaidi (2015). Given that a run-of-river hydroelectric plant is to be constructed, the water discharge and elevation drop are needed to generate hydroelectricity. In this regard, a small dam (intake) is built that conveys water from the main water channel to a pipeline or penstock. The penstock further directs the flow to a power house with a turbine. In this study, multiple possible locations for the hydropower plants are selected at a distance of 1000 meters along the river thalweg line, to mark proposed plant locations. The elevation of each site is extracted from a DEM, and the head difference for that site is the difference between the upstream elevation and the site elevation, where the upstream elevation is taken to be the intake point and the site elevation corresponding to the turbine location. In this case of discharge estimation for the various sites, use is made of the fifty percent exceedance (Q50) values from the two discharge points along the river. The Q50 value of the flow at Melong Gauging station is $38.05 \mathrm{~m}^{3} / \mathrm{s}$ while The Q50 value of the flow at Yabassi Gauging station is $167.74 \mathrm{~m}^{3} / \mathrm{s}$. These two values are used to determine the discharge at the other sites. The theoretical power is then calculated for each of the sites. Multi-criteria analysis in QGIS is then used to select the appropriate site, depending on for example: the capacity of the energy, slope of the area, and others.

\section{Calculation of Energy to Export to the Central Grid}

The objective at this step is to analyse the technical and financial viabilities of possible projects, at the same time reducing the duration of pre-feasibility / feasibility studies (Kobbina, 2014). The hydropower plant together with some estimated dimensioning were accomplished through the use of the RETScreen 4 software suite. RETScreen is a Clean Energy Management Software system for efficient renewable energy and cogeneration project feasibility analysis as well as on-going energy performance analysis (Kobbina, 2014). 


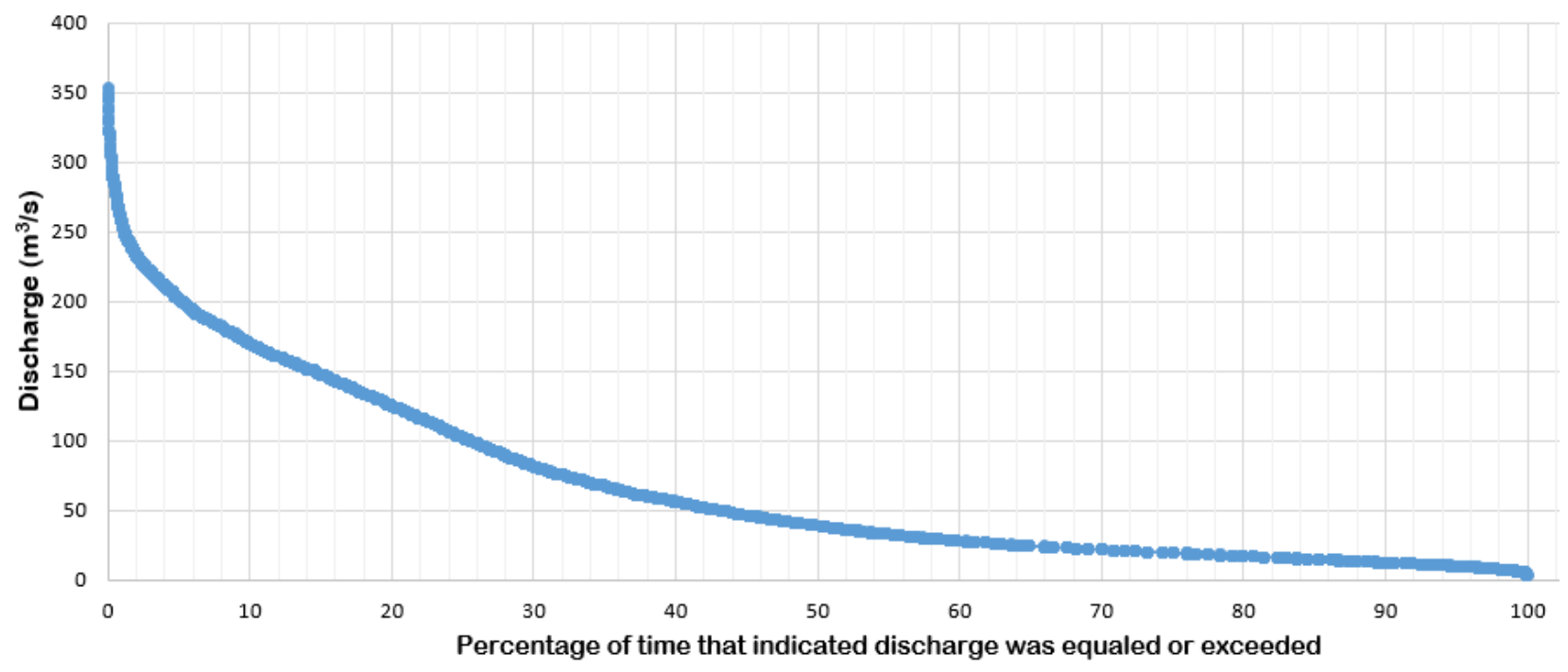

Figure 2. Flow duration curve for River Nkam at Melong (flow data from 1951 - 1991)

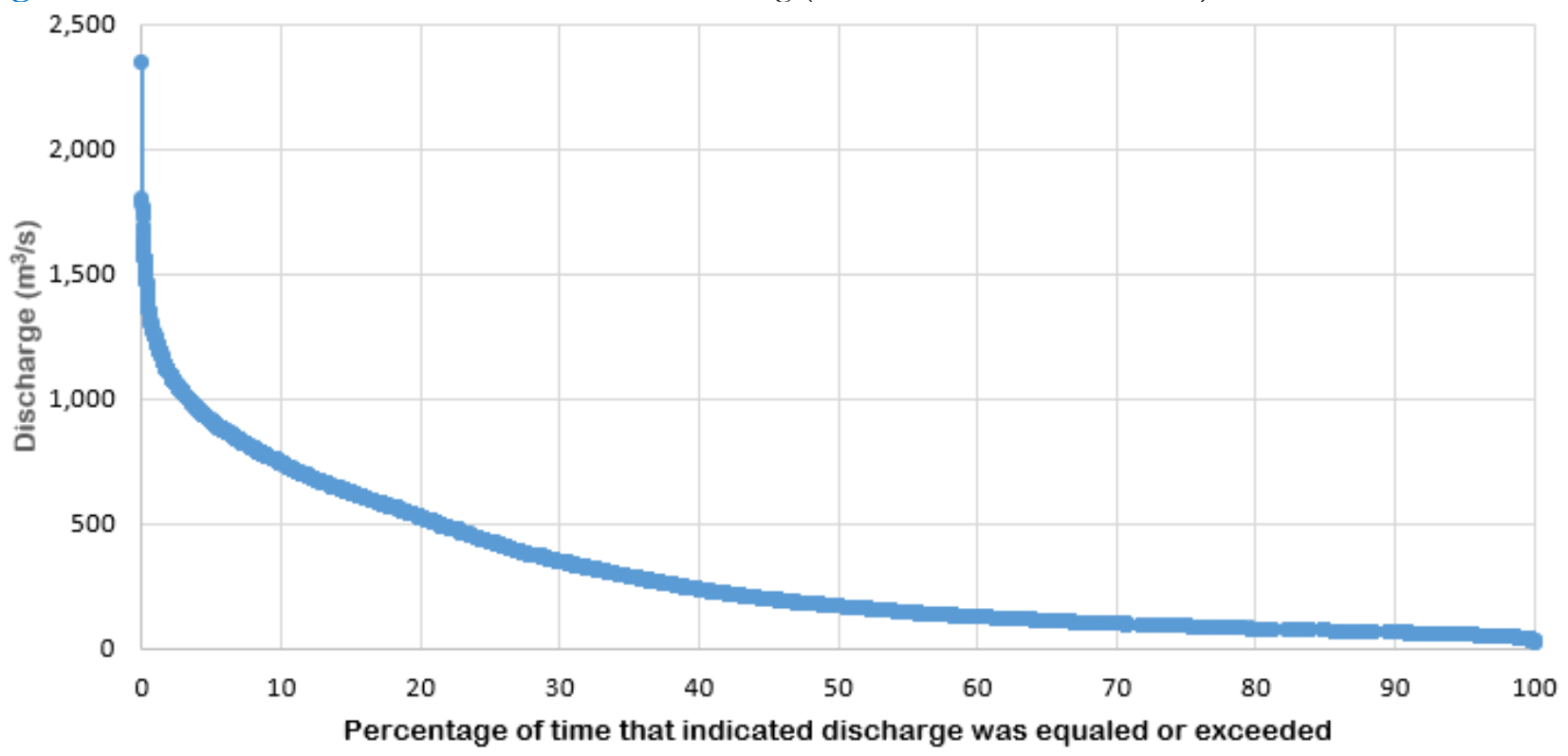

Figure 3. Flow duration curve for River Wouri at Yabassi (flow data from 1951 - 1991)

\section{RESULTS AND DISCUSSION}

The delineated dendritic catchment area was approximately $8,191.66 \mathrm{~km}^{2}$. Two outflow points were used to divide it into two sub-basins, given that only two discharge gages were available. Approximately $40 \%$ of the land use is made up of mosaic vegetation (50-70\% grassland/shrub land/forest and $20-50 \%$ cropland) while $47 \%$ of the superficial area is made up of loamy soils (Soil Type Group A), giving the area a good infiltration rate. Thus the runoff depth that results from the net precipitation is not enough to cause flooding within the area, since the value for initial abstraction is reasonably large. With the high rainfall values for the catchment area, and the high retention, we realize that the area will have a correspondingly high value for the groundwater. It is this groundwater (base flow) that has been maintaining flow in the perennial streams of the likes of River Wouri.

The deterministic hydrologic model was calibrated and validated for precipitation and discharge data from Yabassi (the outflow point of the catchment basin) and Melong for 1951 - 1980. The calibrated peak discharge produced an absolute error of $3.4 \%$ and a Nash-Sutcliffe value of 0.301 , for a simulation run of August 01,1985 to August 31, 1985 from daily precipitation values and the validated design discharge gave an absolute error of $8.9 \%$. This big validation error is most probably as a result of approximations from the rainfall data. Getting hourly rainfall data to use for both calibration and validation results in a validated model that reflects the natural catchment basin with the smallest error.

The Flow Duration Curves (plotted with mean daily discharge values) for the two gauged stations at Melong and Yabassi are shown in Figures 2 and 3 respectively. 


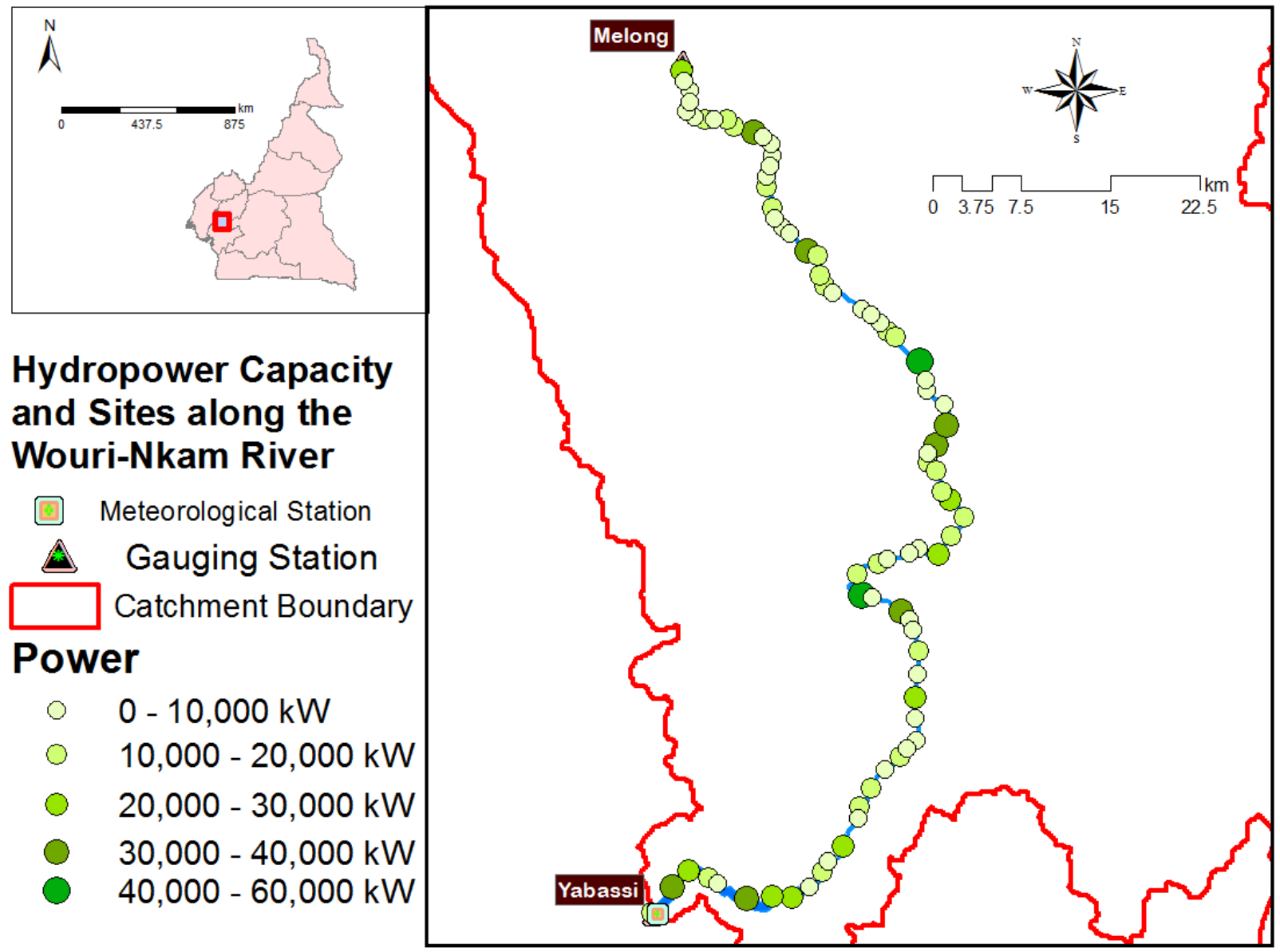

Figure 4. The theoretical potentials of hydropower calculated along the Wouri-Nkam River

The theoretical potentials of hydropower calculated along the Wouri-Nkam River is shown in Figure 4.

A design flow value was taken to correspond to Q69.8, from the flow duration curve of Figure 3. The gross head was chosen to be $20 \mathrm{~m}$ and the turbine type was Francis. The turbine peak efficiency was calculated to give $85.9 \%$ while the generator efficiency was estimated at $95 \%$. The calculated power stood at $13,813 \mathrm{~kW}$. The capacity of power to be exported to the central grid is calculated at $111,180 \mathrm{MWh}$ at $\$ 52.50$ per MWh. The nominal flow was obtained from the flow duration curve of the flow in Figure 3. This flow corresponds to the flow value observed 120 days during a year. The compensation flow, which is the minimum flow in the river to sustain aquatic life, is calculated from the nominal flow to give $133.17 \mathrm{~m}^{3} / \mathrm{s}$.

Renewable energy projects like the hydropower projects do contribute in mitigating the effects of climate change, by reducing the amount of carbon dioxide in the atmosphere. The gross annual Green House Gases emission reduction in terms of tons of carbon dioxide that will be obtained by implementing this project stands at 27,064.8. This is equivalent to 2,489 hectares of forest absorbing carbon dioxide.

\section{CONCLUSION}

The Kyoto Protocol advocates the production of renewable energies like the hydropower, but this hydropower generation passes through a number of stages. The most important of the steps concerns the hydrological analysis, which permits to get the geomorphic parameters of the area of interest as well as the available discharge for generating the hydroelectricity. A number of software were used to accomplish this step, including WMS, HECHMS, and QGIS, to delineate the area contributing in terms of runoff to the outlet point at Yabassi. It was also assumed that the rainfall depth is uniformly constantly distributed over the whole area, because only one meteorological station at Yabassi was used. Nonetheless, a reasonable estimate was made for the hydropower at $13,813 \mathrm{~kW}$ (due to advancement in remote sensing techniques) corresponding to Q69.8. It turned out that the projects along the Wouri - Nkam River vary between Small Hydropower Plant (with energy capacity between 1 and $25 \mathrm{MW}$ ) and Medium Hydropower Plant (with energy capacity between 25 and $100 \mathrm{MW}$ ). This study will aid decision-makers in making informed judgements concerning improvement in the available energy of the country 
to reduce load shedding. The developed blueprint will be used to assess the hydropower potential of the country in general.

A detailed feasibility study will have to be carried out to better plan a harnessing approach and cost-effectiveness of the project. This include doing comprehensive geologic, geomorphic, seismic, and geotechnical studies on the study area.

\section{ACKNOWLEDGEMENT}

We are indebted to the Xuan Thien Africa Investment S.A in Yabassi, through whom we received the discharge and precipitation data for this work. They are concerned with the designing and construction of hydraulic structures like dams, hydropower stations, and others, and are currently carrying out some feasibility studies on a part of the catchment basin

\section{REFERENCES}

Coskun, H. G., Alganci, U., Eris, E., Agrralioglu, N., Cigizoglu, H. K., Yilmaz, L. and Toprak, Z. F. (2010). Remote Sensing and GIS Innovation with Hydrologic Modelling for Hydroelectric Power Plant (HPP) in Poorly Gauged Basins. Water Resour. Manag., 24, 3757-3772. https:/ /doi.org/10.1007/s11269-010-9632-x

Dudhani, S., Sinha, A. K. and Inamdar, S. S. (2006). Assessment of small hydropower potential using remote sensing data for sustainable development in India. Energy Policy, 34, 3195-3205. https:// doi.org/10.1016/j.enpol.2005.06.011

Fan, F., Deng, Y., Hu, X. and Weng, Q. (2013). Estimating Composite Curve Number Using an Improved SCSCN Method with Remotely Sensed Variables in Guangzhou, China. Remote Sens., 5, 1425-1438. https://doi.org/10.3390/rs5031425

Khan, M. and Zaidi, A. Z. (2015). Run-of-River Hydropower Potential of Kunhar River, Pakistan. Pak. J. Meteorol., 12.

Kobbina, J. A. (2014). Assessment of a typical small hydropower site for rural electrification in the western region of Ghana. College of Engineering, pp. 118.

Kulkarni, S. and Banerjee, R. (2011). Renewable Energy Mapping in Maharashtra. India Using GIS., pp. 3177-3184.

Mirchi, A., Watkins Jr., D. and Madani, K. (2010). Modeling for watershed planning, management, and decision making (Nova Science Publishers, New York).

Nations, W. W. A. P. (United, UN-Water, and Unesco (2009). Water in a Changing World (UNESCO).

Raghu, N. P. (2015). Delineation of run of river hydropower potential of Karnali basin - Nepal using GIS and HEC-HMS. Euro. J. Adv. Engg. Tech., 2, 50-54.

Tarife, R. P., Tahud, A. P., Gulben, E. J. G., Ignacio, M. T. T. and others (2017). Application of Geographic Information System (GIS) in Hydropower Resource Assessment: A Case Study in Misamis Occidental, Philippines. Int. J. Environ. Sci. Dev., 8, 507. https://doi.org/10.18178/ijesd.2017.8.7.1005 